\title{
Construction of a Shuttle Vector for Heterologous Gene Expression in Escherichia coli and Microalgae Anabaena
}

\author{
Donghui Song ${ }^{*}$, Jing Li, Xiaoxu Hu, Bo Xi \\ Tianjin Key Laboratory of Marine Resources and Chemistry, College of Marine Science \& Engineering, \\ Tianjin University of Science \&Technology, Tianjin, China \\ Email: *dhsong@tust.edu.cn
}

Received 2013

\begin{abstract}
The construction of an integrative shuttle expression vector and potential utility was reported in Escherichia coli and Anabaena (Nostoc) sp. strain PCC 7120. The vector comprised of the following elements: (a) an intergenic non-coding region from Anabaena to facilitate its genomic integration (b) a strong functional $\mathrm{P}_{p s b A I}$ promoter from Anabaena for desired gene expression and (c) neomycin phosphotransferase gene with its own promoter for the selection of transformants. The constructed vector pAnFP was evaluated by cloning, transfer and expression of the $g f p$ gene encoding green fluorescent protein. When the E. coli and Anabaena sp. strain PCC 7120 were transformed, intensive green fluorescence produced by the products of GFP protein was observed. This result indicated that the integrative shuttle vector pAnFP can be promisingly used in genome transformation for expression of heterologous genes in E. coli and microalgae such as Anabaena and Nostoc strains.
\end{abstract}

Keywords: Anabaena sp. PCC 7120; Integrative Shuttle Vector; pAnFP; gfp Gene

\section{Introduction}

In the last few years, microalgae have been extensively investigated for biotechnological applications as a rich source of bioactive compounds [1], for biofuels production [2,3], and for nitrogen biofertilizer [4]. Filamentous nitrogen fixing microalgae Anabaena have been particularly interesting since they harbor vital processes of photosynthesis and nitrogen fixation [5,6]. Apart from much research on heterocyst development, Anabaena strains have been known for their ability to overproduce biohydrogen for potential utilization as a clean and renewable biofuels $[7,8]$. Genetic engineering is one approach for microalgal strains to produce more lipids-rich cells. Two primary requirements must be fulfilled before a microalgal strain can be successfully engineered in this manner. One is that these expressible and recombinant genes which affect lipid metabolism must be available; another requirement is often effective approach which should be developed to incorporate stably cloned exogenous genes into host cells [9]. Strain Anabaena (Nostoc) sp. PCC 7120 (referred to in this paper as Anabaena 7120) has been chosen for this study since its genome is completely sequenced and it is amenable to genetic manipulation. More importantly is that the development of stable integrative expression system will benefit from the

"Corresponding author. well developed molecular genetics of Anabaena 7120 . Therefore, we reported here a construction of integrative shuttle vectors, pAnFP, for inserting exogenous genes into microalgae Anabaena 7120.

\section{Materials and Methods}

\subsection{Strains and Culture Conditions}

Bacterial strains and plasmids used in this study are shown in Table 1. Anabaena 7120 was grown in BG11 medium without nitrate [10], $\mathrm{pH} 7.2$, at $27^{\circ} \mathrm{C}$. E. coli strains were grown in Luria Bertani (LB) medium with appropriate antibiotics when required. Antibiotics were used at $100 \mu \mathrm{g} / \mathrm{ml}$ Ampicillin (Amp) and $50 \mu \mathrm{g} / \mathrm{ml} \mathrm{ka-}$ namycin (Km) for $E$. coli and $25 \mu \mathrm{g} / \mathrm{ml}$ neomycin $(\mathrm{Nm})$ in BG11 agar media or $12.5 \mu \mathrm{g} / \mathrm{ml}$ in liquid BG11 media for Anabaena transformants.

\subsection{Molecular Biology Methods}

Standard molecular biology techniques were used [11]. Anabaena 7120 chromosomal DNA was isolated as described [12]. DNA fragments from Anabaena 7120 were amplified using the polymerase chain reaction (PCR) with appropriate primers shown in Table 2. The nptII gene (encoding neomycin phosphotransferase) and $g f p$ gene (encoding green fluorescent protein) was independently PCR amplified from plasmid pET-30a(+) and 
Table 1. Bacterial strains and plasmids.

\begin{tabular}{|c|c|c|}
\hline Strains and plasmids & Characteristics & Source \\
\hline \multicolumn{3}{|l|}{ Bacterial strains } \\
\hline E. coli TOP10 & recAslacU169 & Invitrogen \\
\hline $\begin{array}{l}\text { Anabaena (Nostoc) sp. } \\
\text { strain PCC7120 }\end{array}$ & wild type & Pasteur \\
\hline \multicolumn{3}{|l|}{ Plasmids } \\
\hline pET-30a $(+)$ & $\mathrm{Km}^{\mathrm{r}}$ & Novagen \\
\hline pGFP & $A m p^{r}$ & Clontech \\
\hline pBluescript II SK (+) & $\mathrm{Amp}^{\mathrm{r}}$ & TakaRa \\
\hline pTF2 & $A m p^{r}$ & This study \\
\hline pTF1 & $A m p^{r}$ & This study \\
\hline $\mathrm{pTP}_{p s b A I}-\mathrm{F} 2$ & $\mathrm{Amp}^{\mathrm{r}}$ & This study \\
\hline pTF1- $\mathrm{P}_{p s b A I}-\mathrm{F} 2$ & $A m p^{r}$ & This study \\
\hline pAnFP & $A m p^{r}, K^{r}$ & This study \\
\hline pAnFP-gfp & $\mathrm{Amp}^{\mathrm{r}}, \mathrm{Km}^{\mathrm{r}}$ & This study \\
\hline
\end{tabular}

pGFP, respectively. Re-introduction of plasmids harboring with gene $g f p$ by triparental conjugation [13] into Anabaena 7120 wild-type cells were used to determine whether these plasmids were responsible for the gene expression and growth phenotypes. Complete nucleotide sequence analysis of all the components of pAnFP vector was carried out by dideoxy sequencing method using appropriate primers (Table 2). The sequence identity of cloned fragments with the known Anabaena 7120 genome sequence was evaluated using the BLAST algorithm (GenBank database, http://blast.ncbi.nlm.nih.gov/, and Kazusa DNA Research Institute, http:/genome.kazusa.or.jp/cyanobase/Anabaena).

\subsection{Fluorescence Microscopy}

The green fluorescence expressing images of $E$. coli and Anabaena 7120 were obtained by light excitation at 365 $\mathrm{nm}$ and were captured by light emission at $510 \mathrm{~nm}$ with an AxioCam HRc camera attached to a Carl Zeiss LSM 510 META NLO microscope.

\section{Results}

\subsection{Construction of an Integrative Shuttle Expression Vector pAnFP}

The plasmid pBluescript II SK (+), hereafter referred as pBS-T, was chosen for construction of the integrative expression shuttle vector pAnFP comprised of (1) flanking regions F1 and F2 for integration, (2) Anabaena promoter $\left(\mathrm{P}_{p s b A I}\right)$ for expression of the downstream gene, (3) the nptII gene for selection of the transformants with
Table 2. Primers designed for pcr amplification.

\begin{tabular}{|c|c|c|}
\hline Components & Sequences & $\begin{array}{l}\text { Restriction } \\
\text { sites }\end{array}$ \\
\hline \multirow{6}{*}{ F1 } & Forward & \multirow{3}{*}{ EcoRI } \\
\hline & 5'-CCGGAATTCACGCCATAATC & \\
\hline & ATGTGTC-3' & \\
\hline & Reverse & \multirow{4}{*}{ PstI } \\
\hline & 5'-TGCACTGCAGTGGGGATAAT & \\
\hline & TACAACTC-3' & \\
\hline \multirow{6}{*}{ F2 } & Forward & \\
\hline & 5'-CGCGGATCCCСССАATTTTG & \multirow[t]{2}{*}{ BamHI } \\
\hline & AAACCTATC-3' & \\
\hline & Reverse & \multirow{4}{*}{ XbaI } \\
\hline & 5'-CTAGTCTAGAGGCTCACСATA & \\
\hline & GGTGAATGCAC-3' & \\
\hline \multirow{5}{*}{$\mathrm{P}_{p s b A 1}$} & Forward & \\
\hline & 5'-GAGCTGCAGGGATTCCCAAA & \multirow[t]{2}{*}{ PstI } \\
\hline & GATAGGG-3' & \\
\hline & Reverse & \\
\hline & 5'-CTCGGATCCCCATATGTTTTT & NdeI \\
\hline \multirow{6}{*}{ nptII } & Forward & \multirow{4}{*}{$\begin{array}{l}\text { BamHI/ } \\
\text { ClaI }\end{array}$} \\
\hline & 5'-CGGGATCCCATCGATACTCA & \\
\hline & CGTTAAGGGAT-3' & \\
\hline & Reverse & \\
\hline & 5'-CGGGATCCCAGGTGGCACTTT & BamHI \\
\hline & TCGGGGA-3' & \\
\hline \multirow{5}{*}{$g f p$} & Forward & \multirow{3}{*}{ NdeI } \\
\hline & 5'-CCGCATATGACATATGAGTAA & \\
\hline & AGGAGAACAAC-3' & \\
\hline & Reverse & \multirow[b]{2}{*}{ ClaI } \\
\hline & $\begin{array}{l}\text { 5'-CGCATCGATTTATTTGTATAGT } \\
\text { TCATCC-3' }\end{array}$ & \\
\hline
\end{tabular}

Underlined and bold regions of the primer sequences represent the incorporated restriction endonuclease sites.

its own promoter in transgenic Anbeana, and (4) ampicillin marker on pBS-T for the positive selection of recombinants in E. coli. The 931 bp F region (for flanking) was selected from an 1192 bp intergenic, non-coding region separating the ORFs alr3857 and alr3858 of Anabaena 7120 genome (Anabaena chromosome 4654700-4655631). Individual elements of the pAnFP vector were PCR amplified using specific primer pairs shown in TABLE II and sequentially cloned at indicated sites (Figure 1(a)). The $\mathrm{F}$ region was amplified separately as two fragments F1 and F2. The vector pAnFP was constructed in three steps (Figure 1(b)): (a) The 431 bp F2 fragment was PCR amplified from Anabaena 7120 DNA, restriction digested with the enzymes BamHI and $\mathrm{XbaI}$ and ligated to $\mathrm{pBS}$ vector at BamHI and XbaI sites. A putative $p s b A I$ promoter region was selected from the upstream region of the psbAI gene, which encodes the D1 protein of photosynthetic apparatus. A 182 bp PCR amplified $\mathrm{P}_{p s b A I}$ product was restriction digested with the enzymes PstI and BamHI and ligated to construct pTF2 at identical sites. The resulting construct $\mathrm{pTP}_{p s b A I}-\mathrm{F} 2$ on independently digestion with $\mathrm{XbaI} / \mathrm{BamHI}$ and $\mathrm{XbaI} / \mathrm{PstI}$ released the 431 bp F2 fragment and F2 $+\mathrm{P}_{p s b A I}$ fragment (Figures 2(a) and (b)). An NdeI site introduced in the $\mathrm{P}_{\text {psbAI }}$ reverse primer (TABLE II) provided an appropriate 


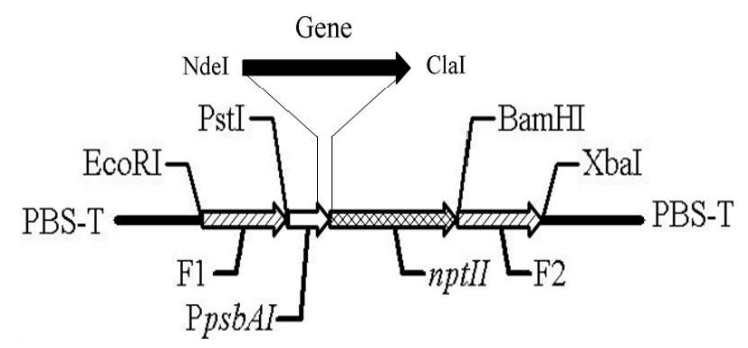

(a)
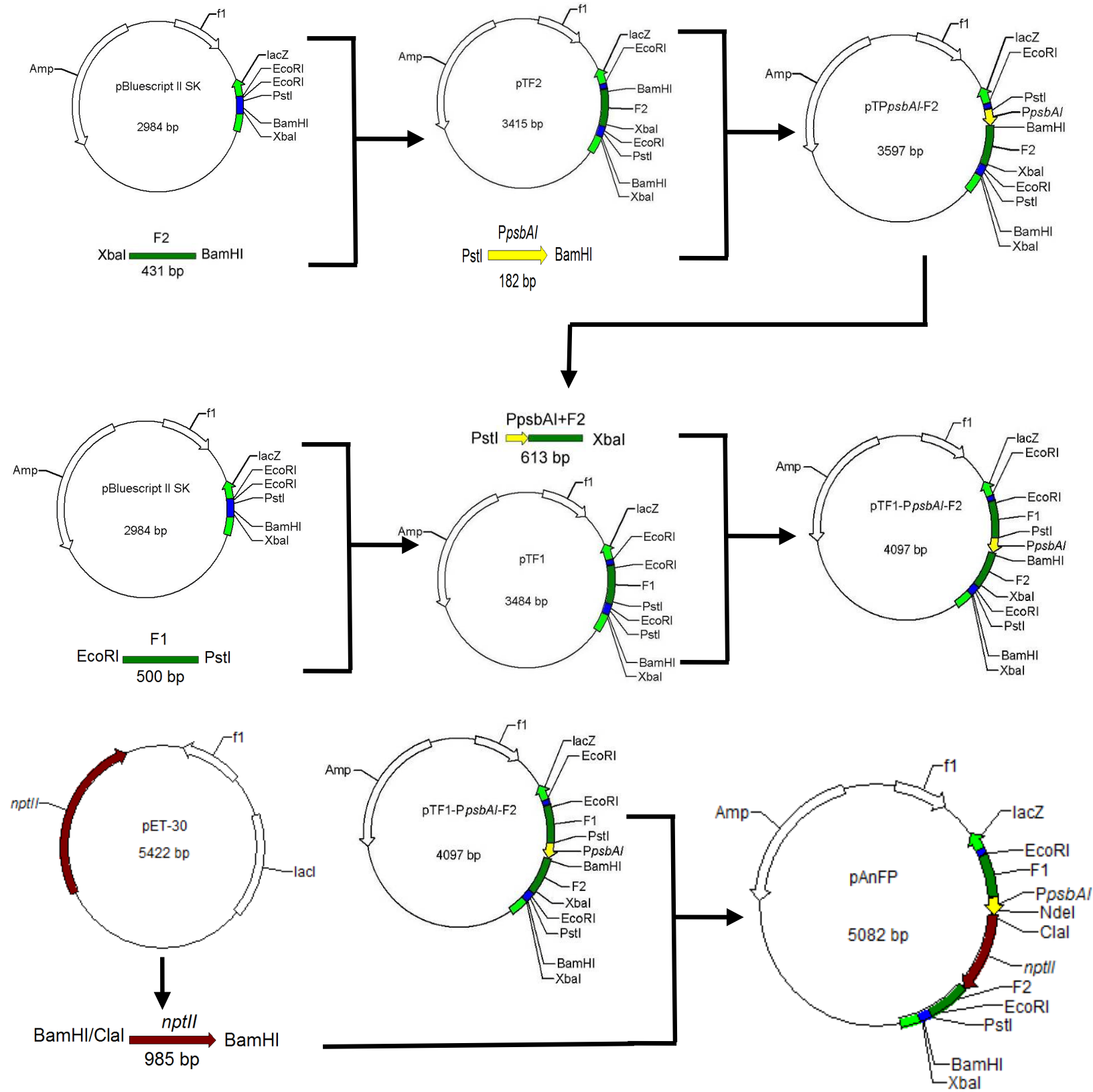

(b)

Figure 1. Construction of integrative shuttle vector pAnFP. (a) Schematic diagram of the integrative expression cassette, containing two flanking regions F1 and F2 for homologous recombination, a promoter PpsbAI, appropriate cloning sites downstream to the promoter (NdeI-ClaI) and a nptII gene, cloned in pBS-T. (b) Flow diagram of pAnFP construction showing the precursor vector along with steps (a), (b), and (c). 


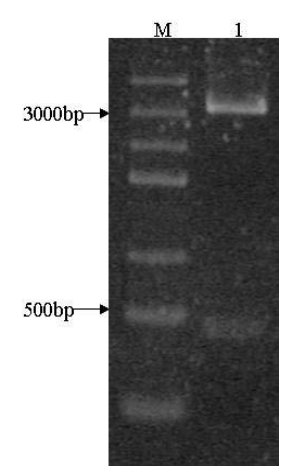

(a)

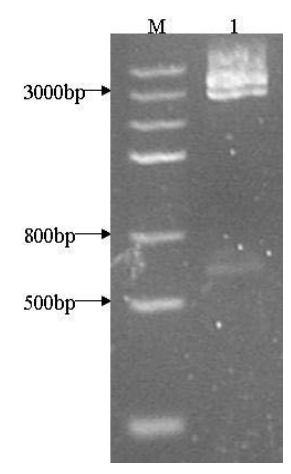

(b)

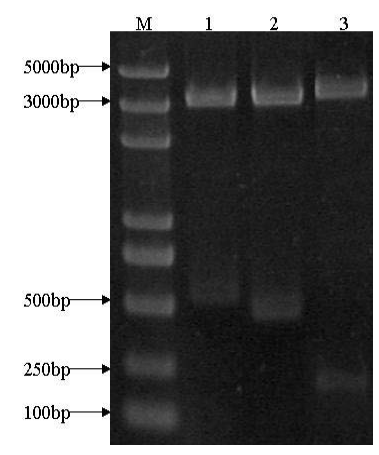

(c)

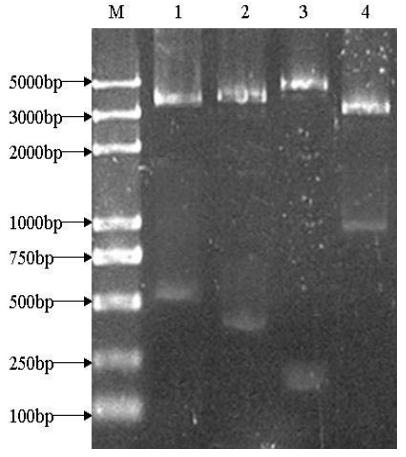

(d)

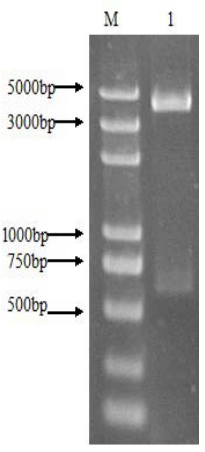

(e)

Figure 2. Experimental verification of pAnFP construction. (a) The construction of clone $\mathbf{p T P}_{p s b A 1}-\mathrm{F} 2$, containing $\mathbf{P}_{p s b A 1}$ promoter and F2 cloned into pBS. M: DNA Marker III; lane 1: pTP psba1 $_{-F 2}$ digested with XbaI/BamHI. (b) The construction of clone $\mathbf{p T P}_{p s b a 1}-\mathrm{F} 2$, containig $\mathrm{P}_{p s b A 1}$ promoter and F2 cloned into pBS. M: DNA Marker III; lane 1: construct

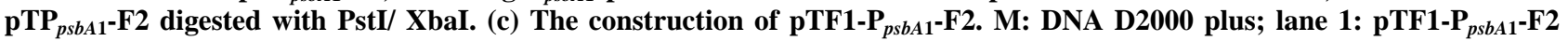
digested with EcoRI/PstI; lane 2: pTF1-P psba1 $_{-F 2}$ digested with XbaI/BamHI; lane 3: pTF1-P psba1-F2 digested with PstI/BamHI. (d) The final assembly of pAnFP vector, containing F1, F2, $P_{p s b A 1}$ promoter and nptII gene. M: DNA D2000 plus; lane 1: pAnFP digested with EcoRI/PstI; lane 2: pAnFP digested with XbaI/BamHI; lane 3: pAnFP digested with PstI/ BamHI; lane 4: pAnFP dige- sted with BamHI. (e) Identification of pAnFP-gfp digestion with NdeI/ClaI. M: DNA D2000 plus.

site for the cloning and expression of a desired gene in the vector. (b) A 500 bp PCR amplified F1 fragment was digested with EcoRI and PstI, ligated to pBS vector at the same sites, and designated as construct pTF1. The $613 \mathrm{bp}$ XbaI-PstI fragment carrying $\mathrm{P}_{p s b A I}+\mathrm{F} 2$ from construct $\mathrm{pTP}_{p s b a l}-\mathrm{F} 2$ was ligated into construct pTF1 at the XbaI and PstI sites. The resulting construct pTF1- $\mathrm{P}_{p s b A I}-\mathrm{F} 2$ on digestion with XbaI and PstI released the 500 bp F1 fragment (Figure 2(c), lane 1). (c) Neomycin phosphortransferase gene (nptII), conferring resistance to neomycin, was amplified from the plasmid pET-30a(+), using nptII forward and reverse primers (TABLE II) as a 985 bp PCR product. This fragment was digested with Bam$\mathrm{HI}$ to obtain a $985 \mathrm{bp}$ fragment which was ligated into the same sites of pTF1- $\mathrm{P}_{p b A I}-\mathrm{F} 2$, resulting in the construction of a $5.082 \mathrm{~kb}$ integrative expression vector, pAnFP. The vector pAnFP on digestion with the enzymes released 500bp F1, 431bp F2, 182bp $\mathrm{P}_{p s b A I}$ and 985bp nptII (Figure 2(d)).

\subsection{Expression of the Shuttle Vector pAnFP with Gfp Gene in Escherichia coli and Anabaena 7120}

Green Fluorescent Protein (GFP) has been used as a marker of gene expression in microalgae [14]. To evaluate ability of pAnFP as a potential integrative shuttle expression vector, a $g f p$ gene from the pGFP plasmid was PCR amplified by using $g f p$ primers (Table 2). The 717 bp PCR amplified DNA fragment was restriction digested with NdeI and ClaI and cloned into the NdeI and ClaI digested pAnFP vector to yield plasmid pAnFP-gfp. Digestion of pAnFP-gfp with NdeI and ClaI yielded 717 bp $(g f p)$ and $5 \mathrm{~kb}$ pAnFP fragments (Figure 2(e)). The inserted gene was transformed into E. coli TOP10 and Anabaena 7120 as described in methods, respectively. Transformants of $E$. coli and Anabaena 7120 harboring with the recombinant vector pAnFP-gfp were observed strong green fluorescent expression (Figure 3)). This result showed that the integrative vector pAnFP-gfp has successfully expressed in both $E$. coli and Anabaena 7120.

\section{Discussion}

The expression of $g f p$ gene in E. coli and Anabeana 7120 indicated that the integrative shuttle expression vector pAnFP can be promisingly used in genome transformation of cyanobacteria such as Anabaena strains. Plasmid pAnFP contains an integrative cassette and offers a novel combination of many desirable features. A gene of interest can be cloned downstream of a strong $\mathrm{P}_{p s b a l}$ promoter of Anabaena, integrated in the chromosome of Anabaena at an innocuous location and expressed. The vector pAnFP makes it more attractive for applications in the chromosomal integration and makes it amenable for subsequent tracking. Moreover, using of a promoter driven by a naturally available stimulus is eco-friendly and does not change the circadian expression of genes of microalgae [15]. The $\mathrm{P}_{p s b A 1}$ promoter from other sources has earlier been used for expression of desired genes in Anabaena [16] and in other cyanobacteria [17] and plants [18]. Our findings indicate that the pAnFP vector bearing heterologous genes can be successfully expressed in $E$. coli and be used for transformation of cyanobacteria such as Anabaena or Nostoc strains in the future. The integrative shuttle expression vector pAnFP may prove the way to generate desired transgenic microalgae for the bioactive 


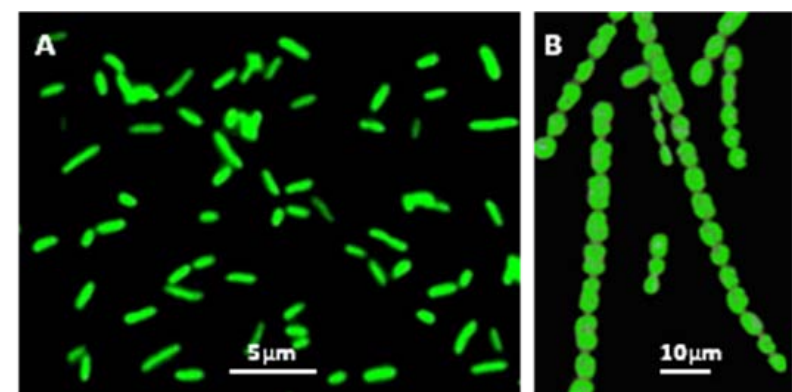

Figure 3. Expression of $g f p$ gene in $E$. coli and Anabaena 7120 . Cells were excited at $365 \mathrm{~nm}$ and emitted at $510 \mathrm{~nm}$ to visualize green fluorescence of GFP. (A) E. coli strains carrying pAnFP-gfp. (B) Anabaena 7120 strains carrying pAnFP-gfp.

compounds or biofuels production which can be varying potential utility of basic research and industrial applications.

\section{REFERENCES}

[1] P. Bhadury and P. C. Wright, "Exploitation of Marine Algae: Biogenic Compounds for Potential Antifouling Applications,” Planta, Vol. 219, No. 4, 2004, pp. 561-578. http://dx.doi.org/10.1007/s00425-004-1307-5

[2] A. Singh, P. S. Nigam and J. D. Murphy, "Renewable Fuels from Algae: An Answer to Debatable Land Based Fuels,” Bioresource Technology, Vol. 102, No. 1, 2011, pp. 10-16. http://dx.doi.org/10.1016/j.biortech.2010.06.032

[3] D. H. Song, J. J. Fu and D. J. Shi, "Exploitation of OilBearing Microalgae for Biodiesel," Chinese Journal of Biotechnology, Vol. 24, No. 3, 2008, pp. 341-348. http://dx.doi.org/10.1016/S1872-2075(08)60016-3

[4] A. K. Chaurasia and S. K. Apte, "Improved Eco-Friendly Recombinant Anabaena PCC 7120 Strain with Enhanced Nitrogen Biofertilizer Potential," Applied and Environmental Microbiology, Vol. 77, No. 2, 2011, pp. 395-399. http://dx.doi.org/10.1128/AEM.01714-10

[5] W. D. Stewart, "Some Aspects of Structure and Function in $\mathrm{N}_{2}$-Fixing Cyanobacteria," Annual Review of Microbiology, Vol. 34, 1980, pp. 497-536. http://dx.doi.org/10.1146/annurev.mi.34.100180.002433

[6] P. Lindberg, P. Lindblad and L. Cournac, "Gas Exchange in the Filamentous Cyanobacterium Nostoc punctiforme Strain ATCC 29133 and Its Hydrogenase-Deficient Mutant Strain NHM5," Applied and Environmental Microbiology, Vol. 70, No. 4, 2004, pp. 2137-2145. http://dx.doi.org/10.1128/AEM.70.4.2137-2145.2004

[7] H. Masukawa, K. Inoue, H. Sakurai, C. P. Wolk and R. P. Hausinger, "Site-Directed Mutagenesis of the Anabaena sp. Strain PCC 7120 Nitrogenase Active Site to Increase Photobiological Hydrogen Production,” Applied and Environmental Microbiology, Vol. 76, No. 20, 2010, pp. 6741-6750. http://dx.doi.org/10.1128/AEM.01056-10

[8] P. D. Weyman, B. Pratte and T. Thiel, "Hydrogen Production in Nitrogenase Mutants in Anabaena variabilis,”
FEMS Microbiology Letters, Vol. 304, No. 1, 2010, pp. 55-61.

http://dx.doi.org/10.1111/j.1574-6968.2009.01883.x

[9] A. B. M. Hossain, A. Salleh, A. N. Boyce, P. Chowdhury and M. Naqiuddin, "Biodiesel Fuel Production from Algae as Renewable Energy,” American Journal of Biochemistry and Biotechnology, Vol. 4, No. 3, 2008, pp. 250254. http://dx.doi.org/10.3844/ajbbsp.2008.250.254

[10] R. W. Castenholz, “Culturing of Cyanobacteria,” Methods in Enzymology, Vol. 167, 1988, pp. 68-93. http://dx.doi.org/10.1016/0076-6879(88)67006-6

[11] J. Sambrook, F. E. Fritsch and T. Maniatis, "Molecular Cloning: A Laboratory Manual,” 2nd Edition, Cold Spring Harbour Laboratory Press, New York, 1989.

[12] J. Paz-Yepes, E. Flores and A. Herrero, "Expression and Mutational Analysis of the $g \ln B$ Genomic Region in the Heterocyst-Forming Cyanobacterium Anabaena sp. Strain PCC 7120, ” Journal of Bacteriology, Vol. 191, No. 7, 2009, pp. 2353-2361.

http://dx.doi.org/10.1128/JB.01381-08

[13] C. C. Bauer, K. S. Ramaswamy, S. Endley, L. A. Scappino, J. W. Golden and R. Haselkorn, "Suppression of Heterocyst Differentiation in Anabaena PCC 7120 by a Cosmid Carrying Wild-Type Genes Encoding Enzymes for Fatty Acid Synthesis, ” FEMS Microbiology Letters, Vol. 151, No. 1, 1997, pp. 23-30.

http://dx.doi.org/10.1111/j.1574-6968.1997.tb10390.x

[14] A. Kunert, M. Hagemann and N. Erdmann, "Construction of Promoter Probe Vectors for Synechocystis sp. PCC 6803 Using the Light-Emitting Reporter Systems gfp and LuxAB," Journal of Microbiological Methods, Vol. 41, No. 3, 2000, pp. 185-194. http://dx.doi.org/10.1016/S0167-7012(00)00162-7

[15] O. A. Koksharova and C. P. Wolk, "Genetic Tools for Cyanobacteria,” Applied Microbiology and Biotechnology, Vol. 58, No. 2, 2002, pp. 123-137. http://dx.doi.org/10.1007/s00253-001-0864-9

[16] A. K. Chaurasia, A. Parasnis and S. K. Apte, “An Integrative Expression Vector for Strain Improvement and Environmental Applications of the Nitrogen Fixing Cyanobacterium, Anabaena sp. strain PCC7120," Journal of Microbiological Methods, Vol. 73, 2008, pp. 133-141. http://dx.doi.org/10.1016/j.mimet.2008.01.013

[17] N. F. Tsinoremas, A. Kawakami and D. A. Christopher, "High-Fluence Blue Light Stimulates Transcription from a Higher Plant Chloroplast psbA Promoter Expressed in a Cyanobacterium, Synechococcus (sp. Strain CC7942)," Plant and Cell Physiology, Vol. 40, No. 4, 1999, pp. 448452. http://dx.doi.org/10.1093/oxfordjournals.pcp.a029562

[18] Y. Yabuta, M. Tamoi, K. Yamamoto, K. Tomizawa, A. Yokota and S. Shigeoka, "Molecular Design of Photosynthesis-Elevated Chloroplasts for Mass Accumulation of a Foreign Protein,” Plant and Cell Physiology, Vol. 49, No. 3, 2008, pp. 375-385. http://dx.doi.org/10.1093/pcp/pcn014 